\title{
Functionalization of LDPE and mLLDPE via grafting trans-ethylene-1,2-dicarboxylic acid by reactive extrusion
}

\author{
Yu. M. Krivoguz 1 , A. M. Guliyev², S. S. Pesetskii ${ }^{*}$ \\ ${ }^{1}$ Department of Technology of Polymeric Composite Materials and Particles V.A. Belyi Metal-Polymer Research Institute \\ of National Academy of Sciences of Belarus, 32a Kirov Street, 246050 Gomel, Republic of Belarus \\ ${ }^{2}$ Institute of Polymer Materials National Academy of Sciences of Azerbaijan, 124 S.Vurgun Street, Az 5004 Sumgait, \\ Azerbaijan Republic
}

Received 16 October 2009; accepted in revised form 22 December 2009

\begin{abstract}
An investigation was made of grafting trans-ethylene-1,2-dicarboxylic acid (TEDA) onto metallocene-linear low-density polyethylene (mLLDPE) and low-density polyethylene (LDPE) in the course of reactive extrusion. The initiator was 1,3-bis-(tert-butyl-peroxyisopropyl)benzene. The graft efficiency of TEDA has been shown to increase with increasing initiator concentration, irrespective of polyethylene type. The graft values for LDPE were higher than for mLLDPE over the initiator concentration range (0.05 to $0.4 \mathrm{wt} \%$ ). The rheological properties of mLLDPE were found to undergo more tangible changes during functionalization than those of LDPE. These changes were caused by side reactions, mainly macromolecular crosslinking. It has been established that some carboxyl groups get transformed to anhydride groups in the grafted product. The concentration of end double bonds reduces, but intramolecular unsaturation in both polyethylenes increases. Data are presented on thermal and stress-strain (mechanical) properties of virgin and functionalized polymers, as well as rheological and viscoelastic properties of their melts.
\end{abstract}

Keywords: material testing, low-density polyethylene, linear low-density polyethylene, funtionalization, trans-ethylene-1,2dicarboxylic acid

\section{Introduction}

Functionalization of polymers and copolymers of olefins via grafting polar monomers (or oligomers) onto macromolecules in melt by reactive extrusion has been studied for several decades. However, the importance of fundamental and applied investigations into this problem still holds and even is becoming more pressing. This is explained, on the one hand, by lack of a quantitative theory required to calculate the course of both main reactions and side processes in reacting systems. On the other hand, technological equipment, particularly extrusion compounding reactors, has been updated continually, which should be taken into consideration in choosing optimal technological parameters for functionalization. Besides, the necessity of solving applied problems requires that basic research be done into functionalization of various olefin copolymers [1-7], polyethylene (PE) and polypropylene (PP) blends $[8,9]$ as well as blends of polyolefins $(\mathrm{PO})$ with copolymers of ethylene and higher olefins $[10,11]$, copolymers of ethylene and vinyl acetate [12], linear polyethylene [13] and others.

It should be noted that most studies of fundamental nature have been concerned with functionalization of PE and PP of conventional grades. Results of those studies have been reported in reviews and books [14-19]. It has been learned that saturated PO functionalization by grafting polar monomers

*Corresponding author, e-mail: otdel5mpri@ tut.by

(c) BME-PT 
onto their macromolecules in melt and grafted product output depends on the nature of reactants (polymer, initiator of radical reactions, monomer to be grafted), composition of the reacting system and on a set of technological factors of which melt temperature, reaction period, degree of shear effect upon the melt are most important [16, 19, 20]. It is believed that at monomer grafting onto saturated $\mathrm{PO}$, the free radicals, formed as a result of initiator decomposition, break away mobile hydrogen from macromolecules, while macroradicals formed interact with monomers making them grafted [18, 21]. There has been found a difference in the mechanisms and kinetics of side reactions during PE and PP functionalization: PE macromolecules undergo crosslinking for the most part, while PP macromolecules suffer degradation owing to $\beta$-decomposition of macroradicals which are formed at interaction with the initiator.

A number of basic laws explain the mechanism and kinetics of monomer grafting, but there are unsolved problems preventing the understanding of macromolecular transformations in greater detail. Particularly, it isn't clear what is the role of unsaturated (double) bonds - contained in PO macromolecular structure - in the reactions of functionalization? What is the character of double bond transformations, and how the total saturation level varies in the course of functionalization? What is the specific influence of molecular structure (degree of macromolecular branching, type of unsaturation, etc.) upon grafted product ratio and transformation of different double bonds during free-radical reactions taking place at monomer grafting?

Clarification of some aspects of these problems is dealt with in this work; its main task is to analyze the specificity of grafting a carboxyl-containing monomer onto different modifications of low density polyethylene, and to determine values of important properties of the prepared materials.

\section{Experimental}

\subsection{Materials}

The objects for analysis were low-density polyethylene (LDPE) (supplied by 'Polimir' Co., Republic of Belarus; Grade 15803-020; melting temperature $T_{m}=113^{\circ} \mathrm{C} ;$ crystallization temperature $T_{c r}=$ $89.5^{\circ} \mathrm{C}$ as determined by the differential scanning calorimetry (DSC) technique at a heating rate of $16^{\circ} \mathrm{C} / \mathrm{min}$ ) and metallocene linear low-density polyethylene (mLLDPE) (supplied by DOW Co., USA; Grade Elite 5400S; $T_{m}=125.8^{\circ} \mathrm{C} ; T_{c r}=$ $\left.103.7^{\circ} \mathrm{C}\right)$. The monomer to be grafted was transethylene-1,2-dicarboxylic acid (TEDA) (the IUPAC name is fumaric acid, quality 'Pure', supplied by Komtex Co., Russia); 1,3-bis-(tert-bulyl peroxyisopropyl)benzene (Grade Perk-14, supplied by Azko Nobel, Netherlands; $\left(\tau_{0,5}=0.31 \mathrm{~min}\right.$ at $200^{\circ} \mathrm{C}$, the reactive oxygen concentration $9 \%$ ) was the initiator.

\subsection{Preparation of functionalized $P E$}

The process of functionalization (monomer grafting) was run in the twin-screw extruder TSK 35/40 (Chengdu Pu Rui Polymer Engineering Co., Ltd., China; $D=35 \mathrm{~mm} ; L / D=40$; the number of heating zones was 10); the screws were equipped with special compounding elements (two mixing sections of cam-type and one section of screw-type to ensure melt mixing in the opposite direction to the mainstream flow).

The reaction zone temperature in the extruder was $230^{\circ} \mathrm{C}$. The concentration of TEDA grafted onto LDPE and mLLDPE was constant in all of the experiments making $1 \mathrm{wt} \%$; the content of Perk-14 was varied between 0.05 and $0.4 \mathrm{wt} \%$.

\subsection{Methods of analysis of the materials}

The grafting efficiency $(\alpha)$ and melt flow index (MFI) were the parameters to characterize the course of grafting reaction and side processes, as it had been done elsewhere [20].

Values of $\alpha$ were determined using film samples of thickness $40 \mu \mathrm{m}$ with absorption IR-spectroscopy technique based on analysis of grafted monomer content in TEDA functionalized polyethylene (PEg-TEDA) before and after extraction with acetone (Equation (1)):

$$
\alpha=\frac{A_{\tau}}{A_{0}} \cdot 100
$$

where $A_{0}$ and $A_{\tau}$ are, respectively, integral absorption intensities of carbonyl (areas of respective absorption bands) at $1600-1875 \mathrm{~cm}^{-1}$ before and after extraction of films in acetone.

IR-spectra were recorded with Fourier Transform Infrared (FTIR) spectroscope Nicolet 5700 (USA). 
Table 1. FTIR transmittance peaks for unsaturated bonds

\begin{tabular}{|c|c|c|}
\hline Group & Structure & $\begin{array}{c}\text { Wavenumber } \\
{\left[\mathrm{cm}^{-1}\right]}\end{array}$ \\
\hline Vinylidene & & 888 \\
\hline Vinyl & $\mathrm{RCH}=\mathrm{CH}_{2}$ & $909 ; 995$ \\
\hline trans-Vinylene & & 965 \\
\hline cis-Vinylene & & 740 \\
\hline
\end{tabular}

The resolution was $4 \mathrm{~cm}^{-1}$; the number of scans was 60.

Unsaturated groups were analyzed using absorption bands at $850-1000 \mathrm{~cm}^{-1}$ (Table 1). The analysis was pursued of double bonds belonging to vinyl, vinylidene and trans-vinylene groups [22, 23]. It was impossible to define cis-vinylene via infrared spectrum because the absorption band at $740 \mathrm{~cm}^{-1}$ was overlapped with the intensive band of pendulum oscillations of $-\mathrm{CH}_{2}-$ groups at $720 \mathrm{~cm}^{-1}$ $[22,23]$.

The IR-spectra were treated mathematically using computer program OMNIC (Version 7.1) which includes functions to construct base lines and calculate integral intensities of absorption bands. The arithmetic mean values for integral intensities were obtained from analysis of nine samples (relative error of a single measurement did not exceed $1 \%$ ). Polymer melt viscosities were estimated by the flow index which was determined at $230^{\circ} \mathrm{C}$ under $10 \mathrm{~kg}$ load using the IIRT-AM device (Ukraine).

Thermal properties of the polymers were judged by the data of DSC. The study was carried out on Perkin Elmer Diamond DSC microcalorimeter (Shelton, USA); the sample weight $=5 \mathrm{mg}$, heating $/$ cooling rate $=16^{\circ} \mathrm{C} / \mathrm{min}$. To eliminate effects of thermal pre-history of samples upon structure, measurements were done on samples pre-heated in cells of the calorimeter up to $160^{\circ} \mathrm{C}$, thermostated at this temperature for $60 \mathrm{~s}$, then used for analysis. High elastic properties of melts of initial and functionalized LDPE and mLLDPE were judged by their strength (Equation (2)):

$\sigma_{m}=\frac{M}{S_{c}}$ where $M$ is the extrudate weight at which it is separated from the capillary; $S_{c}$ the area of capillary bore; and by swell index of melt jet (Equation (3)):

$$
B=\frac{D_{e}}{D_{c}}
$$

where $D_{e}$ and $D_{c}$ are, respectively, diameters of extrudate and capillary. Values of $\sigma_{m}$ and $B$ were found following the procedure described elsewhere [8]; the capillary diameter was $1.45 \mathrm{~mm}$; length = $2 \mathrm{~mm}$.

Stress-strain (mechanical) properties of the materials were determined on samples injection moulded at $170^{\circ} \mathrm{C}$. Tensile tests were performed on Instron Universal Testing Machine Series 5567 (United Kingdom) according to ISO R527 at a loading (pulling) rate of $50 \mathrm{~mm} / \mathrm{min}$.

\section{Results and discussion}

\subsection{Graft efficiency and MFI of materials}

It is evident from Figure 1 that, irrespective of PE type, an increase in Perk-14 concentration in a reacting mix causes a rise in $\alpha$-values. In both polymers, side reactions of macromolecular crosslinking occur simultaneously with grafting, which is understood from lower MFI (higher viscosity) of LDPE and mLLDPE grafted with TEDA (LDPE-gTEDA and mLLDPE-g-TEDA). It should be mentioned that for mLLDPE, the crosslinking process occurs more actively than in grafting of TEDA onto LDPE. This can probably result from differences in structure of the polymers under investigation.

It is well known, that LDPE macromolecules are characterized by a relatively high degree of branching [23]. Particularly, this polymer contains a great number of short-chain and long-chain side branches randomly distributed along macrochains (the number of $-\mathrm{CH}_{3}-$ groups per 1000 carbon atoms $=21.6$; ethyl-groups $=14.4)$ [24]. The mLLDPE produced with addition of metallocene catalysts, has fewer branches consisting of exclusively short-chain ramified structure the branches of which are regularly distributed along the main chain of the polymer [25]. It can be anticipated that with a higher degree of branching the steric factor will stronger influence the course of chemical macromolecular transformation [26]. It is quite probable that steric hindrances make crosslinking in molten LDPE pro- 

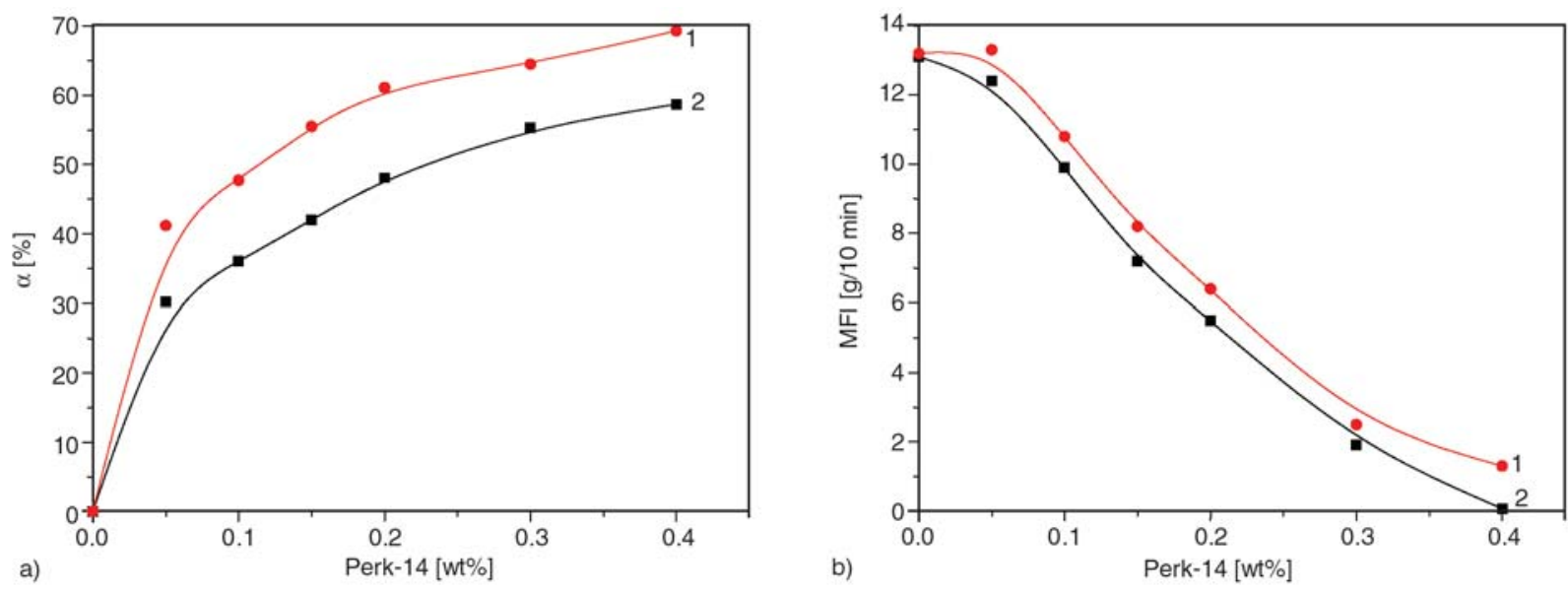

Figure 1. Effect of peroxide concentration on graft efficiency of TEDA (a) and MFI (b) for LDPE-g-TEDA (1) and mLLDPE-g-TEDA (2)

ceed less actively than in molten mLLDPE which has a more linear structure [26].

Crosslinking reactions lead to a higher viscosity of molten mLLDPE-g-TEDA compared with LDPEg-TEDA. A higher viscosity can be harmful for the grafting reaction of a monomer; the rate of this reaction much depends on mobility of macromolecules in melt. On increasing the molten polymer viscosity, diffusion the monomer being grafted onto macroradicals becomes difficult. These macroradicals are formed from hydrogen atoms detached from macromolecules by primary free radicals which generated at thermal decomposition of the initiator. Probably for this reason the grafting rate of TEDA onto mLLDPE is lower than that onto LDPE (Figure 1).

Figure 2 shows that TEDA grafted onto both PE's causes changes in IR-spectra at $1600-1900 \mathrm{~cm}^{-1}$, and new bands appear to indicate presence of oxy-

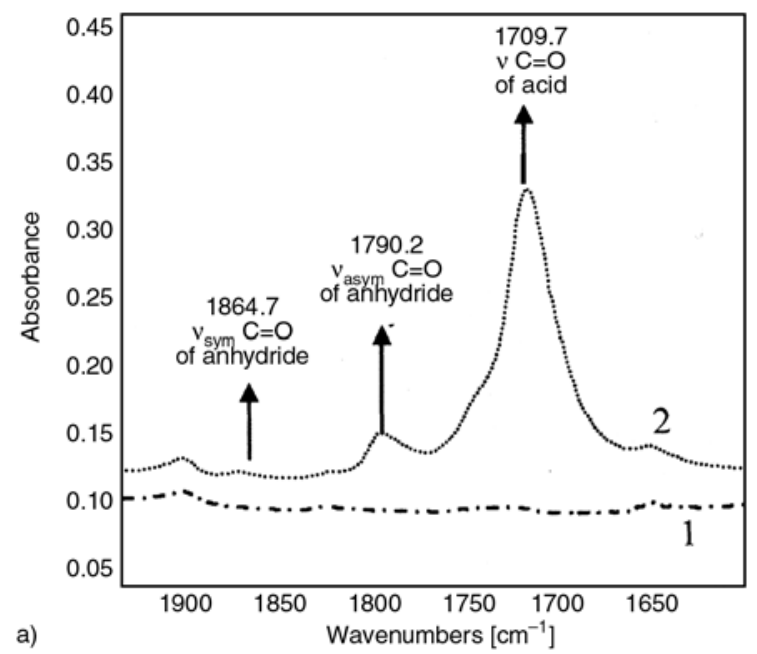

gen-containing functional groups in the macromolecular structure. The band at $1710 \mathrm{~cm}^{-1}$ (Figure 2), unavailable in the spectra of the virgin $\mathrm{PE}$, belongs to valence oscillations of carbonyl groups $\mathrm{C}=\mathrm{O}$ in the structure of carboxyl groups.

The presence of this band in IR-spectra, after films of both PE's have been extracted in acetone, is an indication of the fact that some part of TEDA forms chemical links with macromolecules. In addition to the absorption band at $1710 \mathrm{~cm}^{-1}$, there are peaks at $1760-1880 \mathrm{~cm}^{-1}$ in IR-spectra of PE-g-TEDA. The absorption bands are indicative of cyclic anhydride groups resulting from TEDA grafting onto macromolecules. Existence of grafted anhydride in the PE-g-TEDA is supported by a change in the character of the IR-spectra after the film samples have been treated by water: boiling of the films for $3 \mathrm{~h}$ transformed the anhydride groups to carboxylic ones; the absorption bands at $1790 \mathrm{~cm}^{-1}$ and

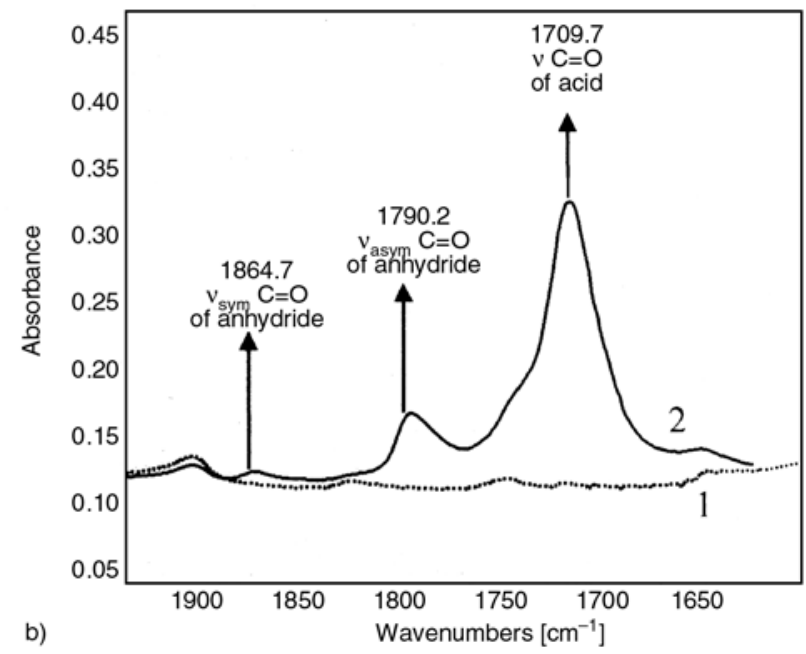

Figure 2. IR-spectra for (a) LDPE (1) and LDPE-g-TEDA (2) and (b) mLLDPE (1) and mLLDPE-g-TEDA (2) 
$1865 \mathrm{~cm}^{-1}$ disappeared. The TEDA is a transisomer, and it cannot form cyclic anhydride in a free state, because carboxylic groups are oriented in different directions with respect to double bonds.

Anhydride can be formed after TEDA has been attached to PE macromolecules or free radicals, when the double bond opens and carboxylic groups can approach each other to react and split out the water. As IR-spectra of PE-g-TEDA differ from those of initial PE by presence of new absorption bands at $1600-1900 \mathrm{~cm}^{-1}$ frequencies caused by valence oscillations of carbonyl $\mathrm{C}=\mathrm{O}$ that belongs to carboxylic or anhydride groups, the grafting efficiency has been determined as a ratio of total bands area of carbonyl absorption (calculated per unit of the film thickness) before and after films extraction with acetone.

\subsection{Analysis of double bonds transformations at $\mathrm{PE}$ functionalization}

Because the chemical structure of the two polymers includes unsaturated groups capable of participating in the reactions of grafting, crosslinking and other transformations, it was of particular interest to analyze their change in the course of LDPE and mLLDPE functionalization. Quantitative variations in the unsaturation character of PE, that occur during TEDA grafting, are evident from the IR-spectra compared for pure and modified polymers (Figure 3 and Table 2). In the pure LDPE spectra, the vinylidene absorption band is more intensive at $888 \mathrm{~cm}^{-1}$, but in LLDPE, the vinyl absorption band is more intensive at $909 \mathrm{~cm}^{-1}$. These differences are explained by characteristic properties of ethylene polymerization with different catalysts [23]. The coefficients of extinction are similar for these groups [27], therefore, the difference observed in band intensities describes their concentration in PE.

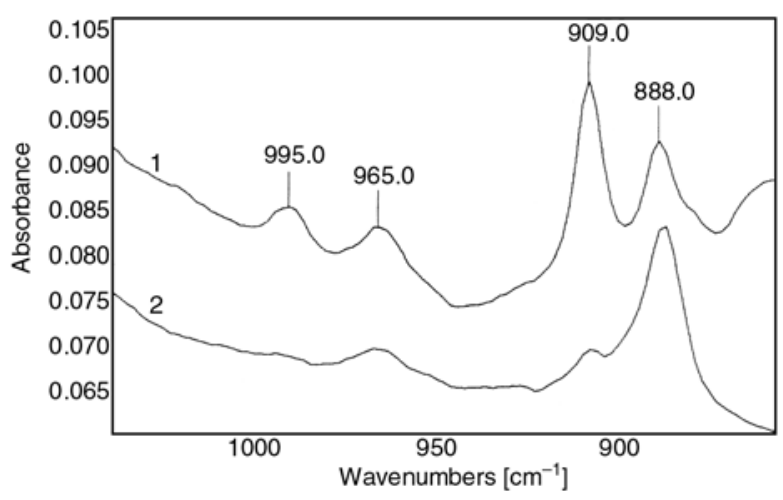

Figure 3. IR-spectra of mLLDPE (1) and LDPE (2) at unsaturated absorption region

Analysis of IR-spectra shows that at grafting of TEDA onto LDPE and mLLDPE, an increase in peroxide initiator concentration causes a reduction in vinylidene as well as vinyl groups. At the same time, the content of trans-vinylene groups increased (Table 2). Consequently, the free-radical grafting of TEDA onto PE changes the unsaturation nature and macromolecular structure. It should be noted, that despite an increased concentration of certain double bonds, the total unsaturation in PE-g-TEDA decreases in comparison with both types of original PE (Table 2). This fact shows that some portion of unsaturated bonds is spent in grafting and side processes (Figure 4). In Table 2, the content of double bonds of certain types is expressed in percent with respect to the total unsaturation being a sum of integral intensities of absorption bands of all unsaturated groups. For an easier understanding, the total unsaturation of initial LDPE and MLLDPE is taken to be $100 \%$. The \%-ratio of PE-g-TEDA total unsaturation to the unsaturation of the initial PE allows to state unambiguously that double bonds participate in the reactions taking place at functionalization. If the contribution of individual types of double bonds to the total unsaturation is known, it

Table 2. Unsaturation in PE as changed by TEDA grafting*

\begin{tabular}{|c|c|c|c|c|}
\hline \multirow{2}{*}{$\begin{array}{c}\text { Perk-14 concentration } \\
\text { [wt\%] for producing }\end{array}$} & \multicolumn{4}{|c|}{ Double bonds content [\%] in original and functionalized PE } \\
\cline { 2 - 5 } PE-g-TEDA & Vinylidene & Vinyl & trans-Vinylene & Total unsaturation \\
\hline 0.00 & $31.8(82.7)$ & $47.6(4.0)$ & $20.6(13.3)$ & $100.0(100.0)$ \\
\hline 0.05 & $31.2(74.1)$ & $46.0(3.7)$ & $22.4(13.9)$ & $99.6(91.7)$ \\
\hline 0.10 & $29.0(71.4)$ & $44.7(3.6)$ & $23.2(14.8)$ & $96.9(89.8)$ \\
\hline 0.15 & $27.0(70.6)$ & $43.4(3.6)$ & $25.0(15.0)$ & $95.4(89.2)$ \\
\hline 0.20 & $26.1(69.2)$ & $42.7(3.3)$ & $26.1(16.5)$ & $94.9(89.0)$ \\
\hline 0.30 & $25.9(66.0)$ & $39.8(3.1)$ & $28.3(19.8)$ & $94.0(88.9)$ \\
\hline 0.40 & $24.3(65.5)$ & $37.2(2.8)$ & $31.0(20.4)$ & $92.5(88.7)$ \\
\hline
\end{tabular}

Note*: Double bond contents: figures outside brackets are for mLLDPE-based materials; those inside brackets, for LDPE -based materials 

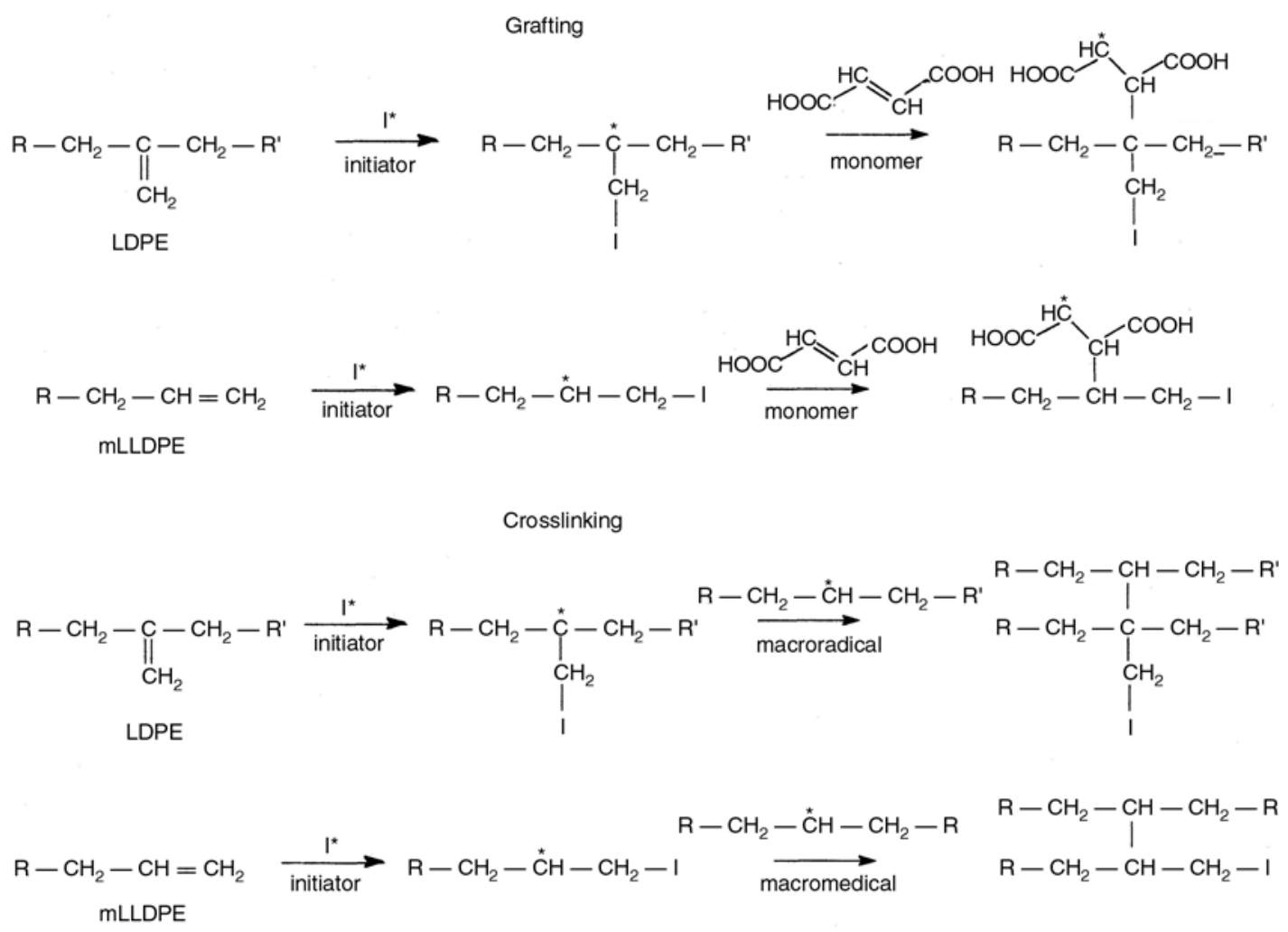

Intramolecular disproportionation

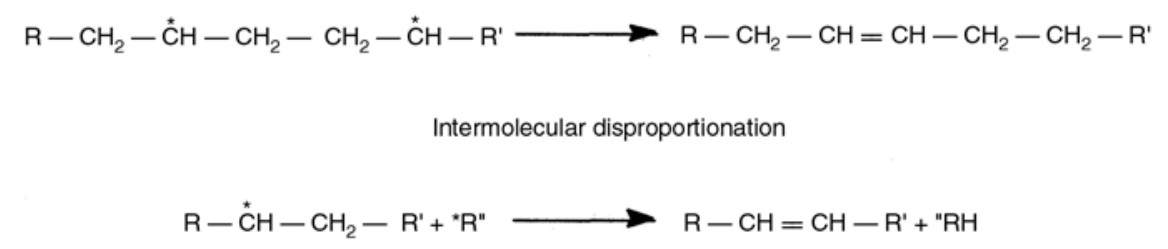

$\beta$-splitting of secondary macroradicals

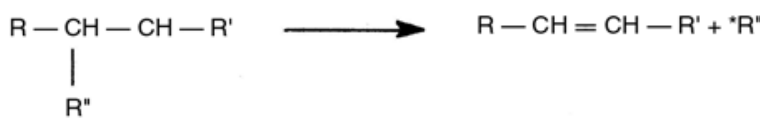

Figure 4. Suggested reactions for grafting monomer onto double bonds of LDPE and mLLDPE, crosslinking and formation of trans-vinylene groups

is possible to judge about their reactivity and degree of transformations.

The FTIR-spectroscopy findings concerning changes in unsaturation of PE during functionalization allow making some assumptions about chemical reactions taking place in free-radical grafting of a monomer. It is worth mentioning that the mechanism of monomer grafting onto $\mathrm{PE}$ has been understood inadequately, and numerous researchers treat it using general theoretical propositions about freeradical chain reactions. There is agreed upon infor- mation, that at free-radical grafting of monomers onto PE, two reactions occur: a major reaction of attaching the monomer to a macrochain and a side reaction of macroradical recombination that leads to macromolecular crosslinking. The occurrence of these reactions has been supported by FTIR- and NMR-spectroscopies and by rheological measurements made on molten grafted products [18].

The results of FTIR-spectral analysis, of how unsaturation varies in functionalized PE, allow a suggestion that free-radical grafting of TEDA onto 
PE leads, besides acid grafting and macromolecular crosslinking, to a number of other macromolecular transformations. For example, an increase in transvinylene concentration, irrespective of $\mathrm{PE}$ type, is indicative of intra- and intermolecular disproportionation, along with $\beta$-splitting of secondary radicals (Figure 4).

It should be mentioned, that $\beta$-splitting of macroradicals during TEDA grafting onto LDPE and mLLDPE is an important characteristic of this process. Reactions of $\beta$-splitting of macroradicals are typical of free-radical grafting of polar monomers onto PP [18]. They result in a decreased molecular weight and viscosity of this polymer. For $\mathrm{PE}$, on the contrary, an increased viscosity is typical. This fact indicates that recombination of macroradicals dominates over their disintegration. It was impossible to follow $\beta$-splitting via analysis of rheological properties of a modified PE. The same is true of disproportionation reactions which do not cause serious variations in polymer rheological properties. These reactions can only be ascertained by analyzing characteristic changes in the unsaturation of a functionalized PE.

Thus, FTIR-spectroscopy data on variations in unsaturation of PE functionalized by free-radial grafting of TEDA onto its macromolecules represent important information for more profound understanding of the grafting mechanism for polar monomers onto macromolecules in the course of reactive extrusion.

\subsection{Results of DSC analysis}

Analysis of data in Table 3 can reveal a characteristic influence of functionalization on PE crystallizability. The melting temperatures of virgin and functionalized PE's containing a peroxide between 0.05 and $0.2 \mathrm{wt} \%$, are close; only with a higher peroxide initiator concentration (up to 0.3 to $0.4 \mathrm{wt} \%$ ) $T_{m}$ values become somewhat lower. The crystal- lization temperature and heat of grafted products, obtained with $0.05-0.2 \mathrm{wt} \%$ of the initiator exceed respective values for the original $\mathrm{PE}$.

Analysis of DSC-data allows a suggestion that TEDA grafted in the presence of small (up to $0.2 \mathrm{wt} \%$ ) concentrations of a peroxide, at which few cross intermolecular bonds are probably formed, facilitates polymer crystallization. A higher peroxide content in reacting systems induces an extra viscosity rise in molten PE-g-TEDA; as a result, crystallization becomes hindered, which manifests itself in a lower enthalpy of crystallization (degree of crystallinity), as well as lower melting and crystallization temperatures.

\subsection{High-elastic properties of PE-g-TEDA melts}

The fitness of polymers and their blends for processing by one or another technology depends not singly on their viscosity but on viscoelastic properties of their melts as well. The latter are characterized, first of all, by strength and swelling of the melt jet [28].

Swelling of an extrudate jet happens owing to normal stresses (Weissenberg effect) caused by applied shear stresses. The swell of extrudate usually enlarges with shear rate when the melt moves through the die and the temperature becomes lower [29-31].

The strength of polymer melt is an important characteristic of extruded and extrusion-blown materials. It much depends on the viscosity, high-elasticity properties of melts, molecular weight of polymers, temperature and other technological parameters [29]. Data on swelling effect of melt jet and the strength of melt are important when choosing a design for the moulding tools, as well as technological parameters of processing, to ensure production of high-quality items.

Table 3. Thermal properties of initial and functionalized mLLDPE and LDPE

\begin{tabular}{|c|c|c|c|c|c|c|}
\hline \multirow{2}{*}{$\begin{array}{c}\text { Peroxide content } \\
{[\mathrm{wt} \%]}\end{array}$} & \multicolumn{3}{|c|}{ mLLDPE-g-TEDA } & \multicolumn{3}{|c|}{ LDPE-g-TEDA } \\
\hline & $\mathbf{T}_{\mathbf{m}}\left[{ }^{\circ} \mathbf{C}\right]$ & $\mathbf{T}_{\mathrm{cr}}\left[{ }^{\circ} \mathbf{C}\right]$ & $\Delta \mathrm{H}_{\mathrm{cr}}[\mathrm{J} / \mathrm{g}]$ & $\mathbf{T}_{\mathbf{m}}\left[{ }^{\circ} \mathbf{C}\right]$ & $\mathbf{T}_{\mathrm{cr}}\left[{ }^{\circ} \mathbf{C}\right]$ & $\Delta \mathrm{H}_{\mathrm{cr}}[\mathrm{J} / \mathrm{g}]$ \\
\hline 0.00 (initial PE) & 125.8 & 103.7 & 145.1 & 113.0 & 89.5 & 108.3 \\
\hline 0.05 & 125.8 & 106.7 & 154.5 & 109.0 & 90.7 & 127.8 \\
\hline 0.10 & 125.2 & 104.7 & 165.6 & 109.8 & 90.1 & 99.1 \\
\hline 0.15 & 126.2 & 103.7 & 121.2 & 110.4 & 90.1 & 97.0 \\
\hline 0.20 & 124.2 & 104.7 & 92.5 & 108.4 & 90.7 & 118.1 \\
\hline 0.30 & 124.2 & 103.7 & 137.5 & 109.4 & 89.7 & 113.5 \\
\hline 0.40 & 122.4 & 99.6 & 125.5 & 110.7 & 88.5 & 123.9 \\
\hline
\end{tabular}


It should be noted, that despite regular studies carried out for many years, the accumulated information on swelling mechanisms and strength of polymer melts mostly refers to virgin $\mathrm{PO}$ and their blends [32-38]. Little information is available on functionalized PO.

Our experimental results on the effect of grafting on melt strength and swelling of molten extrudate for LDPE, mLLDPE, LDPE-g-TEDA and mLLDPE-g-TEDA are given in Table 4. It is clear that mLLDPE has lower melt strength than LDPE. Grafted TEDA improves the mLLDPE melt strength. The rise is especially significant at higher concentrations of the peroxide initiator (between 0.2 and $0.4 \mathrm{wt} \%$ ). The melt strength values for all mLLDPE-g-TEDA compositions are several times lower against similar compositions of LDPE-gTEDA. This great difference in melt strength between LDPE, mLLDPE and functionalized products based on these is explained by the fact that mLLDPE has narrower molecular weight distribution and more linear macromolecular structure than LDPE.

The extrudate swelling values for mLLDPE and mLLDPE-g-TEDA are also lower than for LDPE. The $B$-dependence on mLLDPE-g-TEDA composition is of an extreme nature, unlike that of $\sigma_{m}$ of the melt (Table 4). A maximum swelling is typical of mLLDPE-g-TEDA prepared with peroxide concentrations between 0.05 and $0.2 \mathrm{wt} \%$. A further increase in the peroxide content leads to $B$-reduc- tion. This regularity is peculiar to both types of $\mathrm{PE}$ under consideration. A probable reason for this is the fact that with increased peroxide concentrations, macromolecules of the grafted products undergo crosslinking, which prevents the extrudate jet from swelling.

\subsection{Mechanical properties of the materials}

Table 5 presents results of mechanical testing of functionalized mLLDPE and LDPE. In case of LDPE, it is clear, that variations between 0.05 and $0.4 \mathrm{wt} \%$ of peroxide initiator in a reacting system, cause no appreciable changes in the deformationstrength properties. In case of mLLDPE-g-TEDA, on the contrary, a sharp increase (by $~ 50 \%$ ) in mechanical strength occurs with an increased initiator concentration $(0.4 \mathrm{wt} \%)$ against pure mLLDPE. The relative elongation of functionalized mLLDPE tends to reduce considerably.

Thus, in the course of grafting, mLLDPE experiences greater deformation-strength changes in comparison with LDPE.

\section{Conclusions}

Grafting of TEDA onto LDPE and mLLDPE through reactive extrusion in the presence of peroxide Perk-14 (Perk-14 concentration being varied between 0.05 and $0.4 \mathrm{wt} \%$ ) results in grafted products; the grafting efficiency $\alpha$ varies between $30 \%$

Table 4. High-elasticity properties of initial and functionalized mLLDPE and LDPE melts

\begin{tabular}{|c|c|c|c|c|}
\hline \multirow{2}{*}{ Peroxide content [wt $\%]$} & \multicolumn{2}{|c|}{ mLLDPE-g-TEDA } & \multicolumn{2}{c|}{ LDPE-g-TEDA } \\
\cline { 2 - 5 } & $\boldsymbol{\sigma}_{\mathbf{m}}[\mathbf{k P a}]$ & $\mathbf{B}[$ rel.unit] & 1.8 & 5.0 \\
\hline 0.00 (initial PE) & 1.1 & 4.0 & 16.4 & 5.8 \\
\hline 0.05 & 1.6 & 4.2 & 21.2 & 5.4 \\
\hline 0.10 & 1.8 & 4.2 & 24.2 & 5.0 \\
\hline 0.15 & 2,1 & 4.3 & 28.5 & 4.9 \\
\hline 0.20 & 3.4 & 4.1 & 31.5 & 4.3 \\
\hline 0.30 & 8.7 & 4.0 & 33.5 & 4.3 \\
\hline 0.40 & 12.4 & 3.8 & & $\boldsymbol{\sigma}_{\mathbf{m}}[\mathbf{k P a}]$ \\
\hline
\end{tabular}

Table 5. Stress-strain properties of initial and functionalized mLLDPE and LDPE

\begin{tabular}{|c|c|c|c|c|}
\hline \multirow{2}{*}{ Peroxide content [wt\%] } & \multicolumn{2}{|c|}{ mLLDPE-g-TEDA } & \multicolumn{2}{c|}{ LDPE-g-TEDA } \\
\cline { 2 - 5 } & $\boldsymbol{\sigma}_{\mathrm{t}}[\mathbf{M P a}]$ & $\boldsymbol{\varepsilon}_{\mathrm{t}}[\%]$ & $\boldsymbol{\sigma}_{\mathrm{t}}[\mathrm{MPa}]$ & $\boldsymbol{\varepsilon}_{\mathrm{t}}[\%]$ \\
\hline 0.00 (initial PE) & 18.0 & 265.5 & 14.2 & 79.3 \\
\hline 0.05 & 15.2 & 229.0 & 13.6 & 69.9 \\
\hline 0.10 & 17.1 & 237.7 & 13.4 & 70.5 \\
\hline 0.15 & 18.3 & 242.3 & 13.2 & 65.9 \\
\hline 0.20 & 17.4 & 205.5 & 13.5 & 62.5 \\
\hline 0.30 & 19.8 & 108.4 & 13.5 & 63.5 \\
\hline 0.40 & 26.9 & 60.4 & 13.4 & \\
\hline
\end{tabular}


and $70 \%$. The $\alpha$-value for LDPE-g-TEDA, within the whole concentration range of Perk-14, exceeds by $\sim 10 \%$ that for mLLDPE-g-TEDA. Grafting makes MFI of melts decrease (viscosity becomes higher) for the two polyethylenes; this effect is most pronounced for mLLDPE-g-TEDA over the entire concentration range of the peroxide, which is explained by intensification of side reactions of macromolecular crosslinking. It has been established that in the grafted product, some part of carboxylic groups are transformed to anhydride groups. During TEDA grafting, the concentration of end double bonds becomes lower and intramolecular unsaturation grows in LDPE, as well as is mLLDPE macromolecular structure. The crystallizing tendency of PE-g-TEDA varies depending on the initiator content: with Perk-14 $\leq 0.2 \mathrm{wt} \%$, the crystallizability accelerates, while at higher peroxide doses it decelerates. Functionalization of the two PEs leads to a higher strength and lower swell coefficient of the melts at their leaving the capillary. The mechanical values for LDPE-g-TEDA are similar to the original LDPE, whereas for mLLDPE-g-TEDA the strength rises essentially (upto 1.5 times), but the relative elongation at break reduces 4.4 times at higher concentrations (up to $0.4 \mathrm{wt} \%)$ of Perk-14.

\section{Acknowledgements}

The research has been financially supported by Belarusian Foundation for Fundamental Research, Project NoT07A3003 .

\section{References}

[1] Greco R., Maglio G., Martuscelli E., Musto P., Palumbo P.: Functionalization of an EPR rubber by bulk mixing processes. Polymer Process Engineering, 4, 253-261 (1986).

[2] Greco R., Maglio G., Musto P., Scarinzi G.: Bulk functionalization of ethylene-propylene copolymers. II. Influence of the initiator concentration and of the copolymer composition and chain microstructure on the reaction kinetics. Journal of Applied Polymer Science, 37, 777-788 (1989).

DOI: 10.1002/app.1989.070370314

[3] Greco R., Maglio G., Musto P. V.: Bulk functionalization of ethylene-propylene copolymers. I. Influence of temperature and processing on the reaction kinetics. Journal of Applied Polymer Science, 33, 2513-2527 (1987).

DOI: 10.1002/app.1987.070330720
[4] Greco R., Musto P.: Bulk functionalization of ethylene-propylene copolymers. IV. A theoretical approach. Journal of Applied Polymer Science, 44, 781-788 (1992).

DOI: 10.1002/app.1992.070440505

[5] Zhang X. M., Yin Z. H., Li L. X., Yin J. H.: Grafting of glycidyl methacrylate onto ethylene-propylene copolymer: Preparation and characterization. Journal of Applied Polymer Science, 61, 2253-2257 (1996). DOI: 10.1002/(SICI)1097-4628(19960926)61:13 $\leq 2253::$ AID-APP2>3.0.CO;2-B

[6] Oostenbrink A. J., Gaymans R. J.: Maleic anhydride grafting on EPDM rubber in the melt. Polymer, 33, 3086-3088 (1992). DOI: $10.1016 / 0032-3861(92) 90102-3$

[7] Grigoryeva O. P., Karger-Kocsis J.: Melt grafting of maleic anhydride onto an ethylene-propylene-diene terpolymer (EPDM). European Polymer Journal, 36, 1419-1429 (2000). DOI: $\underline{10.1016 / \text { S0014-3057(99)00205-0 }}$

[8] Pesetskii S. S., Jurkowski B., Krivoguz Y. M., Tomczyk T., Makarenko O. A.: PP/LDPE blends produced by reactive processing. I. Grafting efficiency and rheological and high-elastic properties of [PP/LDPE]-gIA melts. Journal of Applied Polymer Science, 102, 5095-5104 (2006).

DOI: $10.1002 / a p p .24097$

[9] Krivoguz Y. M., Pesetskii S. S., Jurkowski B., Tomczyk T.: Structure and properties PP/LDPE blends grafted with itaconic acid in the course of reactive extrusion. Journal of Applied Polymer Science, 102, 1746-1754 (2006).

DOI: $10.1002 /$ app. 23998

[10] Premphep K., Chalearmthtlpa S.: Melt grafting of maleic anhydride onto elastomeric ethylene-octene copolymer by reactive extrusion. Polymer Engineering and Science, 41, 1978-1986 (2001).

DOI: $10.1002 /$ pen.10894

[11] Jurkowski B., Pesetskii S. S., Krivoguz Y. M.: Functionalization of olefin polymer and copolymer blends in the melt. in 'Polyolefin blends' (eds.: Nwabunma D., Kyu T.) Wiley, New York, 273-308 (2007).

[12] Yin J., Zhang J., Yao Y.: Melt grafting of poly(ethylene-vinylacetate) copolymer with maleic anhydride. Journal of Applied Polymer Science, 102, 841-846 (2006). DOI: $10.1002 / a p p .24320$

[13] Saade-Caballero H. G., Martínez-Colunga J.: Reactive extrusion process for the grafting of maleic anhydride onto linear low-density polyethylene with ultraviolet radiation. Journal of Applied Polymer Science, 113, 3125-3129 (2009). DOI: $10.1002 / a p p .28273$

[14] Moad G.: The synthesis of polyolefin graft copolymers by reactive extrusion. Progress in Polymer Science, 24, 81-142 (1999). DOI: $\underline{10.1016 / \mathrm{S} 0079-6700(98) 00017-3}$ 
[15] Chung M.: Functionalization of polyolefins. Academic Press, San Diego (2002).

[16] Hu G. H., Lambla M.: Fundamentals of reactive extrusion: An overview. in 'Materials Science and Technology' (eds.: Cahn R. W., Haasen P., Krame E. J.) Wiley-VCH, New York, 345-400 (1997).

[17] Xanthos M.: Reactive extrusion: Principles and practice. Hanser, Munich (1992).

[18] Al-Malaika S.: Reactive modifiers for polymers. Blackie, London (1997).

[19] Prut E. V., Zelensky A. N.: Chemical modification and blending of polymers in an extruder reactor. Uspekhi Khimii (Russian Chemical Reviews), 70, 7287 (2001).

[20] Pesetskii S. S., Jurkowski B., Krivoguz Y. M., Urbanowicz R.: Itaconic acid grafting on LDPE blended in molten state. Journal of Applied Polymer Science, 65, 1493-1502 (1997).

DOI: $10.1002 /(\mathrm{SICI}) 1097-4628(19970822) 65: 8$ $\leq 1493:$ AID-APP6>3.0.CO;2-B

[21] Pesetskii S. S., Jurkowski B., Krivoguz Y. M., Kelar K.: Free-radical grafting of itaconic acid onto LDPE by reactive extrusion: I. Effect of initiator solubility. Polymer, 42, 469-475 (2001). DOI: $10.1016 / \mathrm{S} 0032-3861(00) 00356-6$

[22] Tarutina L. I., Pozdnyakova F. O.: Spectral analysis of polymers (in Russian). Khimya, Leningrad (1986).

[23] Polyakov A. V., Duntov F. I., Sofiev A. E., Tumarkin N. Ya., Kondratev Yu. N., Domareva N. M., Goldenberg A. L., Kobyakov V. M., Zernov V. S.: Low-density polyethylene. Fundamentals of commercial synthesis (in Russian). Khimia, Leningrad (1988).

[24] Garbar M. I., Akutin M. S., Egorov I. M.: Handbook of plastics (in Russian). Khimia, Moscow (1967).

[25] White J., Choi D.: Polyethylene, polypropylene and other polyolefins. Professia, St. Petersburg (2006).

[26] Jekins A. D., Ledwith A.: Reactive mechanism and structure in polymer chemistry. Wiley, London (1977).

[27] Mahdavi H., Nook M. E.: Characterization and microstructure study of low-density polyethylene by Fourier transform infrared spectroscopy and temperature rising elution fractionation. Journal of Applied Polymer Science, 109, 3492-3501 (2008).

DOI: $\underline{10.1002 / a p p .28398}$
[28] Kalinchev E. L., Sakovtseva M. B.: Properties and processing of thermoplastics. Khimia, Leningrad (1983).

[29] Rosato D. V., Rosato D. V.: Blow molding handbook. Hanser, Munich (1989).

[30] Vinogradov G. V., Malkin A. Ya.: Rheology of polymers (in Russian). Khimia, Moscow (1978).

[31] Koopmans R. J.: Extrudate swell of high density polyethylene. Part I: Aspects of molecular structure and rheological characterization methods. Polymer Engineering and Science, 32, 1741-1749 (1992).

DOI: 10.1002/pen.760322302

[32] Koopmans R. J.: Extrudate swell of high density polyethylene. Part III: Extrusion blow molding die geometry effects. Polymer Engineering and Science, 32, 1755-1764 (1992).

DOI: $\underline{10.1002 / \text { pen.760322304 }}$

[33] Wong A. C-Y., Cheung V. H. K.: Elongation strength of polyethylene melt. Journal of Materials Processing Technology, 67, 117-119 (1997). DOI: $\underline{\text { 10.1016/S0924-0136(96)02829-4 }}$

[34] Wong A. C-Y., Liang J. Z.: Relations between die swell ratio and melt flow index. Chemical Engineering Science, 52, 3219-3221 (1997). DOI: $10.1016 / \mathrm{S} 0009-2509(97) 00115-2$

[35] Wong A C-Y.: Factors affecting extrudate swell and melt flow rate. Journal of Materials Processing Technology, 79, 163-169 (1998). DOI: $\underline{10.1016 / \mathrm{S} 0924-0136(98) 00006-5}$

[37] Dekmezian A. H., Weng W., Gargia-Franco C. A., Markel E. J.: Melt strength of blends of linear low density polyethylene and comb polymers. Polymer, 45, 5635-5640 (2004).

DOI: $10.1016 /$ j.polymer.2004.03.075

[38] Guadarrama-Medina T. J., Pérez-Gonzalez J., Vargas L.: Enhanced melt strength and stretching of linear low-density polyethylene extruded under strong slip conditions. Rheologica Acta, 44, 278-286 (2005). DOI: $\underline{10.1007 / \mathrm{s} 00397-004-0409-0}$ 